\title{
Research on Course Construction and Teaching Reform of Econometrics in China
}

\author{
Yao-hui $\mathrm{CHEN}^{*}$, Chu-yang HU and Xin-yu WANG
}

School of Economics, Nanjing University of Finance \& Economics, Nanjing, Jiangsu, China

${ }^{*}$ Corresponding author

Keywords: Econometrics; Course Construction; Teaching Reform.

\begin{abstract}
Econometrics is one of the core courses in economics. It emphasizes the use of data for quantitative analysis. In the digital era, courses are becoming increasingly important with the wide range of application, thus placing higher requirements on teaching work. Starting from the current situation of econometrics teaching, this paper finds out the problems commonly existing in the teaching process and proposes new ideas for the construction of the course of econometrics and the reform of teaching in China, so that students can better understand and apply the course knowledge.
\end{abstract}

\section{Introduction}

Econometrics is based on certain economic theories and statistical data. It aims to build econometric models as the main means to make a quantitative analysis of the relationship between random economic variables by using mathematical statistics and information technology, which intends to enable students to master the basic theories and methods of modern economics research and develop their ability to apply econometric model to analyze practical economic problems. P. Samuelson, the famous economist and Nobel Prize winner in economics, even said that the economics after the Second World War was an era of econometrics. In 1998, the Supervision Committee of Economics Teaching at the University of the Ministry of Education first identified that econometrics was one of the eight core courses of economics, indicating that the construction of econometrics in China was going to be scientific, modernized and internationalized.

In recent years, many experts and scholars have conducted effective explorations on this issue. Li Zinai [1] believed that the main direction for the construction and innovation of Chinese econometrics course was to introduce the econometric model, theories, methods and the analysis and diagnosis of data into econometrics teaching system. Nie Honglong and Shen Youhua [2] held that the key to optimizing the teaching effect lay in mobilizing the enthusiasm and initiative of students. The necessary means to optimize the teaching effect of undergraduate econometrics is, through strengthening the process of learning and assessment, to achieve the coordinated development of theoretical teaching and experimental teaching. From the viewpoint of Wang Shaoping and Shi Shuyao [3], it is the key link for the cultivation of the learning and research capability of econometrics to correctly understand and apply the theory and method of the limited samples, especially to innovate and expand the existing methods aiming at the data characteristics. Zhou Chuang [4] pointed out that the econometrics teaching should be problem solving-oriented, and further put forward the trinity teaching system which was guided by the professional questions aiming to mobilize learning initiative, centered on case teaching and experimental teaching to enhance students' problem-solving ability, and supported by theoretical teaching.

\section{Problems in Current Econometrics Teaching}

\subsection{Course setting is unreasonable}

Econometrics, as an important professional course, is a combination of economics, mathematics and statistics. It is set up on the basis of microeconomics, macroeconomics, advanced mathematics, linear algebra, probability theory, mathematical statistics, statistics, etc., putting forward higher requirements for students to learn other basic courses. The basic courses of mathematics for 
students majoring in economics in our country only include advanced mathematics, linear algebra, probability theory and mathematical statistics, and these courses are taught by mathematics teachers of science college who know little about economics and cannot carry out the extension of teaching well. As a result, the teaching content is out of line with the needs of the economics major. Students have spent a lot of time on these courses but could not achieve good results. Econometric modeling involves knowledge of differential equations, dynamic optimization methods, topology, and real-variable functions, which are not taught in higher mathematics. Multiple regression analysis requires the partial differential of matrix and the student's spatial thinking ability, which, however, are not involved in linear algebra teaching. In probability theory and mathematical statistics, the proofs of basic knowledge and statistical properties of statistics are often neglected, which have not been taught as key points. Without the support of the teaching reform of mathematics courses, it is hard to make breakthrough in the cultivation of innovative talents in economics, and it will be even more difficult to further study the intermediate and advanced econometrics. In the teaching process of econometrics, the derivation of mathematical model, the construction of statistics and the proof of statistical properties are generally emphasized. It will affect the learning of students who have knowledge gap in related courses. The classroom often becomes a monologue of teachers since most students major in economics have a weak mathematical foundation and cannot understand the abstract proofs and formula derivation.

Due to the fact that China's students of liberal arts and science are enrolled in economic majors, their mathematical basis is quite different, and students of different majors focus on different courses, which is not suitable for teaching in accordance with the unified objectives. Most universities do not offer econometrics courses at different levels for different types of students.

\subsection{Teaching content is not vivid and novel}

The first is the unreasonable arrangement and compilation of the teaching materials. At present, there are a large number of econometrics textbooks. One is the translation of foreign textbooks, edited by scholars such as Gujarati, Wooldridge and Greene. Compared with foreign textbooks, although there are many versions of domestic textbooks, they do not reflect the training of students' modeling ideas and do not make students realize the importance of econometrics. Those textbooks often place too much emphasis on the derivation of mathematics and mathematical statistics theory, losing the attraction for students. And even many students feel plagued with the theory, and then lose their motivation and confidence in the study of econometrics.

The other is the popular textbooks in China. Although there are some cases, they are relatively outdated, generally macroeconomic cases which ignore the description of the modeling process. They lack vivid and novel teaching cases, which makes the classroom mainly based on traditional lecture-style teaching methods, lacking inquiry teaching as a supplement. Thus, classroom teaching is rigid and cannot arouse students' interest. And many teachers are unwilling to conduct case teaching which is so tedious.

\subsection{The rigid thinking of college teachers to the course teaching}

At present, many colleges and universities often have no innovation in course setting, exclude changes, and are accustomed to traditional teaching methods, so that the teaching mode is rigid which cannot cultivate students' innovative spirit and promote their all-round development. In the digital era, econometrics can be applied in a wider range of fields, and involve more related knowledge of disciplines. However, many university teachers do not pay enough attention to the interdisciplinary study, and seldom make meaningful supplement and expansion in the classroom, leading to students' lack of understanding of interdisciplinary knowledge. So it is difficult for students to independently use what they have learned to solve problems. According to the questionnaire, after the choice of professional direction, students tend to study what they are interested in, but neglect the courses they are unfamiliar with or uninterested in. This situation makes it more difficult to cultivate compound talents. 


\subsection{Disconnection between theoretical teaching and practical teaching}

Econometrics is a methodological discipline. The teaching process is divided into two parts: econometric theory and econometric experiment. The mastery of econometrics needs to achieve the unity of theoretical study and practice, but it is often limited by the teaching conditions. On the one hand, the class hours for econometrics in most colleges in China are less, which can not reflect the econometric status. There are only about 50 hours including computer experiments. Teachers often do not have enough time to explain the relevant theories of econometrics, the time series model, the panel data model and binary choice discrete model that are applied more in practice. As a window for students to understand econometrics methods, econometrics software is a bridge between econometrics theory and practice. The use of software in computer experiment teaching plays an important role in improving students' learning enthusiasm and practical ability. But the computer experiment teaching in most colleges and universities does not get due attention, with only less than 10 hours. Econometrics software is mostly developed abroad, so it is difficult for students to master the software in a short period of time, which will directly affect students' ability to analyze data in practice. If students need to build econometrics models in paper writing and practical application, they still have to spend a lot of time on subsequent research. On the other hand, in terms of the teaching arrangement of econometrics, it first carries on the theoretical teaching, then the software teaching in the computer laboratory. At this time, many students have been unfamiliar with or forgotten the theoretical teaching content. Even under the guidance of the experiment of software operation, they also don't understand the specific operational meaning. Econometrics teaching requires each student to be equipped with a computer. It is difficult for students to complete software operations and demonstrations in class by themselves during the theoretical study.

\section{Ideas and Methods of Econometrics Course Construction and Teaching Reform}

\subsection{Setting up multi-level teaching objectives}

Different training objectives should be established for students of arts and science according to the different enrollment categories of majors in economics. For students of arts, the training aims at thinking innovation and application of econometrics tools. The teaching objectives should focus on the economic theory and cultivate students' ability to analyze the causal relationship between economic variables. Their mastery of economic theory is much better than that of mathematics and mathematical statistics, so mathematical deduction should be diluted in teaching and the application of econometrics software should be emphasized. It is necessary to develop the innovative thinking of students of arts, guide them to discover economic problems, explain with economic theories, and conduct the empirical test with econometrics methods. For students of science, the teaching objectives should focus on theoretical innovation and the teaching of econometrics theory. Students of science have a good foundation in mathematics, so it is necessary to improve their training level. Econometrics should not be limited to applications, but focus on the derivation and proof of relevant econometrics theories.

The teaching objectives vary due to the different credits of different majors and various mathematics foundations of students. Therefore, it is necessary to design different teaching contents according to professional differences. Considering students' weak knowledge of probability theory and mathematical statistics, a certain period of time could be offered for students to review basic contents of interval estimation and hypothesis test of mathematical statistics before teaching the unitary linear regression model, so as to facilitate students to understand and master all kinds of tests of econometrics model and lay a solid foundation for the subsequent theoretical teaching. For majors requiring more econometrics credits, the teaching content should be appropriately enriched. Considering that students often need to establish micro-econometrics model at the enterprise level in their graduation thesis, the micro-econometrics module is thus added on the basis of classical econometrics module and time series module to facilitate students to master the basic theory and practical operation of discrete choice model. For majors requiring less econometrics credits, class hours are less, so it mainly focuses on the theoretical teaching of classical econometrics module and 
time series module.

Many colleges and universities abroad have set up different levels of econometrics courses. Students with different foundations and research directions can independently choose relevant courses.

\subsection{Improving the quality of teachers}

The reform of curriculum cannot do without teachers' recognition and application. It cannot achieve the purpose of teaching only with the innovative curriculum, without teachers' efforts. As mentioned above, the study of econometrics requires a good foundation of many related courses and is often extended to other fields. The processing and analysis of data spread across all walks of life, which is the mainstream of today's economic society. Therefore, colleges and universities should formulate various policies to encourage teachers to actively learn interdisciplinary knowledge, and to develop students' interest in learning in the classroom. Besides, teachers could be sent to finance and data-related enterprises, so as to accumulate practical experience which can be applied to classroom teaching.

\subsection{Strengthening classroom teaching quality}

In the actual teaching process, the teaching reform should be attached great importance, to change the teaching ideas and methods and effectively improve the teaching effect through various measures. Teachers need to change their teaching concepts. They cannot adopt the cramming method of teaching, but emphasize students' leading role in learning, and pay close attention to their response when explaining the principles. According to the students' acceptance ability and feedback as the standard, teachers must adjust in time, reduce some difficult mathematical deduction, pay attention to the systematicness and integrality of theory, and develop students' ability to solve practical problems, so as to improve the teaching effect. The main purpose of learning econometrics is to apply it, not to just master the theory. Therefore, teachers should strive to mobilize students' initiative and interest in learning. For example, the time series model involves a large number of random process and random analysis, which could only be fully understood by students of mathematics with postgraduate level. So when explaining the time series analysis, teachers should moderately reduce some complicated mathematical derivation process, explain the basic principles to the students as simple as possible, and then use classical cases and exercises to train their ability to apply econometrics model in analyzing practical problems. Students with a good foundation, who are good at or interested in mathematical derivation, are encouraged to learn after class and share it in class.

In order to highlight the practical application, the case discussion class should be increased. Each chapter includes at least one case where students are asked to consult information and data, build practical econometric models, write course papers, and deliver a speech in class. This not only improves the students' participation, expression ability and comprehensive utilization ability of knowledge, but also increases the interaction between teachers and students and arouses the enthusiasm and initiative of students in learning, so as to consolidate their theoretical knowledge of econometrics.

\subsection{Reasonably arranging the proportion of theory and practice}

Econometrics involves the necessary theoretical derivation and model test, which are often boring, affecting students' learning enthusiasm. To improve students' learning interest and learning effect, it is necessary to reasonably arrange the proportion of theory and practice. Therefore, the combination of theory and practice in teaching should be emphasized, to improve students' application ability. In addition, it has to learn from the latest research results of excellent textbooks and periodicals and enrich teaching plans and courseware. The basic steps of modeling should be systematically demonstrated from the purpose of modeling, variable selection, data processing, parameter estimation, model testing. The application of econometric software needs to be stressed in teaching. For example, EViews software is used to demonstrate repeatedly to improve students' enthusiasm for learning. 


\subsection{Transforming teaching assessment methods}

In course assessment, on the one hand, the basic theoretical knowledge is assessed in written form. On the other hand, students' application and innovation ability is assessed through experiments. There are two ways of experimental assessment. One is the verifiable experimental operation on the computer, which is the evaluation of students' software mastery and their problem-solving ability, requiring each student to complete the specified experimental exercises on the computer within the prescribed time. The other is the exploratory experiment examination, which requires students to choose economic issues according to their professional direction or interests, collect data, analyze and solve the actual economic problems to form a research report. Thus, theoretical and experimental assessments are combined to truly reflect students' theoretical knowledge and practical ability.

\section{Conclusion}

The course construction of Chinese econometrics has a long way to go. It requires not only a strong theoretical foundation of mathematics and statistics, but also a comprehensive ability to solve practical problems in economic management and computer application. It is a theoretical and practical economics course. Its teaching process is faced with many problems, resulting in a situation where "teachers are difficult to teach and students are difficult to learn". Whether it is theoretical teaching or practical teaching be emphasized is not conducive to improving the teaching effect of econometrics. How to solve the imbalance between theoretical teaching and experimental teaching so that students can master the basic theory and practical skills and develop their innovative ability to analyze and solve practical problems? On the one hand, the teaching reform of econometrics cannot be limited to this course, but has to re-examine the important position of econometrics in economics research. It is necessary to appropriately add related secondary courses, reforming and innovating the teaching mode and method of econometrics, so as to promote the coordinated development of theoretical teaching and practical teaching and improve students' interest in learning and their comprehensive ability. On the other hand, it is necessary to strengthen the educational concept based on process evaluation and include students' performance in the teaching process into the assessment. Through the multi-dimensional evaluation mode of the whole process and diversified assessment methods and contents, students' learning process of econometrics is supervised and they are urged to develop their learning habits, thus, fundamentally, improving the quality of course teaching and cultivating students' ability of solving practical problems by using econometric theories and methods.

\section{Acknowledgements}

Authors are grateful to the Brand Major Construction Project of University in Jiangsu (PPZY2015B103); Teaching Reform Project of Jiangsu (2017JSJG047); Project of Evaluation Committee of Higher Education Society in Jiangsu (Pgwyh07101); Teaching Reform Project of Nanjing University of Finance and Economics (JGZ1805).

\section{References}

[1] Z.N., Li. Innovation and Thinking on the Teaching Content of Econometrics. China University Teaching, Vol. (1), 2010, pp. 18-22.

[2] H.L., Lie and Y.H., Shen. Reform on Theory and Experimental Teaching of Econometrics. Journal of Ningbo University of Technology, Vol. 27 (4), 2015, pp. 119-124.

[3] S.P., Wang and S.Y., Si. On the Capacity Cultivation in Econometrics Teaching. Educational Research, Vol. 33 (7), 2012, pp. 110-114.

[4] C., Zhou. Research on Teaching Reform of Econometrics for Undergraduates Based on Problem Solving. Education Teaching Forum, Vol. (22), 2016, pp. 102-103. 